\title{
Gambaran Tata Cara dan Angka Keberhasilan Penyapihan Ventilasi Mekanik di Ruang Perawatan Intensif Rumah Sakit Dr. Hasan Sadikin Bandung
}

\author{
Richard Pahala Sitorus, ${ }^{1}$ Iwan Fuadi, ${ }^{2}$ Ike Sri Redjeki, ${ }^{2}$ Ardi Zulfariansyah ${ }^{2}$ \\ ${ }^{1}$ EKA Hospital Pekanbaru, ${ }^{2}$ Departemen Anestesiologi dan Terapi Intensif \\ Fakultas Kedokteran Universitas Padjadjaran/Rumah Sakit Dr. Hasan Sadikin Bandung
}

\begin{abstract}
Abstrak
Penyapihan ventilasi mekanik adalah suatu proses pelepasan bantuan ventilator yang dilakukan secara bertahap atau langsung oleh seorang dokter Intensive Care Unit (ICU). Penelitian ini bertujuan mengetahui gambaran tata cara dan angka keberhasilan penyapihan ventilasi mekanik yang dilakukan di ICU Rumah Sakit Dr. Hasan Sadikin (RSHS) Bandung. Metode penelitian ini adalah deskriptif observasional prospektif dan merupakan studi cross sectional. Penelitian ini melibatkan 50 pasien yang dirawat di ICU RSHS Bandung pada bulan Juli-September 2015. Data dicatat dan dikelompokkan sesuai dengan variabel karakteristik tata cara dan angka keberhasilan penyapihan ventilasi mekanik. Hasil penelitian ini menunjukkan tata cara penyapihan ventilasi mekanik yang paling banyak dilakukan adalah once daily trial of $T$ piece sebanyak 22 pasien (44\%) kemudian continous positive airway pressure (CPAP) sebanyak $40 \%$, intermittent trial of T-piece sebanyak 10\%, dan pressure support ventilation (PSV) 6\%. Angka keberhasilan penyapihan ventilasi mekanik sebanyak 44 orang (88\%) dan angka kegagalan penyapihan ventilasi mekanik adalah sebanyak 6 orang (12\%) sehingga harus dilakukan re-intubasi. Tata cara penyapihan ventilasi mekanik yang paling banyak digunakan di ICU RSHS Bandung adalah once daily trial of T piece dan angka keberhasilan penyapihan ventilasi mekanik sebesar $88 \%$.
\end{abstract}

Kata kunci: Angka keberhasilan, tata cara penyapihan, ventilasi mekanik

\section{Procedures and Success Rate of Mechanical Ventilation Weaning in Intensive Care Unit of Dr. Hasan Sadikin General Hospital Bandung}

\begin{abstract}
Mechanical ventilation weaning is a process of withdrawing ventilator assistance gradually or immediately by Intensive Care Unit (ICU) physicians. This study aimed to describe the procedure and the success rate of mechanical ventilation weaning performed at the ICU of Dr. Hasan Sadikin General Hospital (RSHS) Bandung. This was a cross-sectional descriptive prospective observational and study involving 50 patients treated at the ICU of RSHS Bandung during the period of July to September 2015. Data were recorded and classified in accordance with the variable characteristics of the procedure and the success rate of mechanical ventilation weaning. The results indicated that the most widely used mechanical ventilation weaning procedures were T-piece once daily trial in 22 patients (44\%), continous positive airway pressure (CPAP) in 40\%, T-piece intermittent trial in 10\%, and pressure support ventilation (PSV)in 6\%. Mechanical ventilation weaning success rate was $88 \%$ and the failure rate was $12 \%$ (6 patients) which required re-intubation. The most widely used procedure for mechanical ventilation weaning at the ICU of Dr. Hasan Sadikin General Hospital Bandung is T-piece once daily trial and the mechanical ventilation weaning success rate is $88 \%$.
\end{abstract}

Key words: Mechanical ventilation, success rate, weaning procedure

Korespondensi: Richard Pahala Sitorus, dr., SpAn, EKA Hospital Pekanbaru, Jl. Soekarno Hatta km. 6,5 Pekanbaru 28282, Tlpn. (0761) 6989999, Mobile 081321690002, Email infopku@ekahospital.com 


\section{Pendahuluan}

Penyapihan ventilasi mekanik adalah proses pelepasan bantuan ventilator yang dilakukan secara bertahap maupun langsung. Penyapihan pasien dari ventilasi mekanik adalah suatu hal yang penting di Intensive Care Unit (ICU). Sebelum tahun 1973, T-piece trial merupakan metode paling sederhana dalam penyapihan ventilasi mekanik sampai diperkenalkannya metode synchronised intermittent mandatory ventilation (SIMV). Metode penyapihan lain adalah pressure support ventilation (PSV), kombinasi antara SIMV dan PSV, dan continous positive airway pressure (CPAP). ${ }^{1}$

Penyapihan ventilasi mekanik dilakukan jika kondisi pasien telah mengalami perbaikan. Kondisi-kondisi yang telah dapat dilakukan penyapihan seperti gagal napas perbaikan, penghentian obat sedasi dan pelumpuh otot, kondisi kardiovaskular yang stabil, perbaikan metabolik dan elektrolit, serta kemampuan napas yang adekuat. ${ }^{1}$

Penilaian para tim dokter dan perawat di ruang Intensive Care Unit (ICU) penting untuk keberhasilan melakukan pelepasan ventilasi mekanik. Teknik-teknik penyapihan ventilasi mekanik mempunyai pertimbangan masingmasing. Pressure support ventilation atau PSV adalah suatu teknik ventilasi mekanik yang memberikan tekanan tertentu pada saat upaya inspirasi spontan pasien. ${ }^{1}$ Pressure support ventilation (PSV) biasa digunakan pada $21 \%$ pasien dalam proses penyapihan ventilasi mekanik. $^{2}$

Metode Continous positive airway pressure (CPAP) memberikan positive end expiratory pressure (PEEP) selama pasien bernapas spontan yang dapat meningkatkan oksigenasi serta menurunkan kerja napas. Pada suatu hasil penelitian dinyatakan bahwa pemberian PEEP selama upaya napas spontan sangat berguna pada pasien dengan gagal napas hipoksik. Penelitian lain menyatakan bahwa penggunaan CPAP atau T-piece trial sebelum ekstubasi tidak menunjukkan perbedaan signifikan dalam hal oksigenasi maupun waktu penggunaan ventilasi mekanik. ${ }^{2}$

Proses penyapihan ventilator melibatkan dua langkah strategis yang dimulai penilaian kesiapan untuk penyapihan dan diikuti oleh SBT sebagai uji diagnostik yang menentukan tingkat keberhasilan proses penyapihan. ${ }^{3}$ Keberhasilan proses penyapihan didefinisikan sebagai pelepasan bantuan napas dan tidak ada bantuan ventilator selama 48 jam berikutnya. ${ }^{4}$ Keberhasilan penyapihan ventilasi mekanik dapat dilihat dengan menggunakan beberapa kriteria (Tabel 1). ${ }^{5}$

Kegagalan proses penyapihan didefinisikan sebagai kegagalan uji napas spontan atau spontaneous breathing trial (SBT), dilakukan re-intubasi dan atau bantuan ventilasi setelah ekstubasi atau kematian dalam 48 jam setelah ekstubasi. ${ }^{4}$ Kegagalan SBT dapat dilihat dengan menggunakan beberapa kriteria yang sudah diteliti sebelumnya berdasarkan penilaian klinis subjektif maupun secara objektif (Tabel 2). ${ }^{2}$

Protokol penyapihan ventilasi mekanik di ICU Rumah Sakit Dr. Hasan Sadikin Bandung belum ada. Saat ini terdapat berbagai tata cara dalam proses penyapihan ventilasi mekanik. Data pasti angka keberhasilan penyapihan ventilasi mekanik juga belum ada. Penelitian ini bertujuan memperoleh gambaran tata cara dan angka keberhasilan penyapihan ventilasi mekanik di ruang ICU RSUP Dr. Hasan Sadikin Bandung.

\section{Subjek dan Metode}

Penelitian ini adalah deskriptif observasional prospektif dan merupakan studi cross sectional yang dilakukan setelah mendapat persetujuan Komite Etik Penelitian Kesehatan Fakultas Kedokteran Universitas Padjadjaran/Rumah Sakit Dr. Hasan Sadikin Bandung. Penelitian dilakukan pada bulan Juli-September 2015 di ICU Rumah Sakit Dr. Hasan Sadikin Bandung. Subjek penelitian adalah semua pasien yang menjalani prosedur penyapihan ventilasi mekanik di ruang perawatan intensif Rumah Sakit Dr. Hasan Sadikin Bandung. Kriteria inklusi adalah pasien menggunakan ventilasi mekanik, terintubasi, dan usia di atas 14 tahun. Kriteria eksklusi adalah pasien telah dilakukan trakeostomi. Sampel akan dikeluarkan apabila 
Tabel 1 Kriteria untuk Spontaneous Breathing Trial (SBT)

\begin{tabular}{ll}
\hline \multicolumn{1}{c}{ Parameter SBT } & \multicolumn{1}{c}{ Kriteria } \\
\hline Respirasi & $\mathrm{PaO}_{2} / \mathrm{FiO}_{2}>150-200 \mathrm{mmHg}$ dengan $\mathrm{FiO}_{2} \leq 50 \%$ dan $\mathrm{PEEP} \leq 8 \mathrm{cmH}_{2} \mathrm{O}$ \\
& $\mathrm{PaCO}_{2}$ normal atau pada kadar sehari-hari \\
& Pasien mampu memulai usaha napas. \\
Kardiovaskular & Tidak ada bukti iskemia miokard \\
& Denyut jantung $\leq 140$ kali/menit \\
& Tekanan darah adekuat dengan minimal atau tanpa vasopressor. \\
Status mental baik & Pasien dapat dibangunkan, atau Glasgow come scores $\geq 13$. \\
Tidak ada kondisi penyulit & Tidak ada demam \\
& Tidak ada gangguan elektrolit yang signifikan. \\
\hline
\end{tabular}

Dikutip dari: Marino ${ }^{5}$

pasien mengalami ekstubasi spontan.

Setelah mendapatkan persetujuan Komite Etik Penelitian Kesehatan Fakultas Kedokteran Universitas Padjadjaran/Rumah Sakit Dr. Hasan Sadikin Bandung, keluarga pasien yang telah masuk ke dalam kriteria inklusi dan tidak termasuk kriteria eksklusi diinformasikan mengenai penelitian ini dan kemudian diminta persetujuan ikut dalam penelitian (informed consent). Data pasien dicatat dalam lembar penelitian oleh residen anestesi yang bertugas di ICU Rumah Sakit Dr. Hasan Sadikin dan tidak ada intervensi perlakuan dari peneliti terhadap pasien sebagai sampel penelitian.

Data yang dicatat adalah nama, usia, jenis kelamin, diagnosis, lama pemakaian ventilator, dan mode ventilator terakhir. Pencatatan dilakukan sampai pasien ekstubasi. Variabel yang dicatat adalah tata cara penyapihan yang digunakan, waktu dilakukan ekstubasi,

Tabel 2 Parameter Gagal Spontaneous Breathing Trial

\begin{tabular}{|c|c|}
\hline Parameter & Kriteria \\
\hline \multirow[t]{5}{*}{ Penilaian klinis dan subjektif } & Agitasi dan ansietas \\
\hline & Penurunan kesadaran \\
\hline & Diaforesis \\
\hline & Sianosis \\
\hline & $\begin{array}{l}\text { Terdapat peningkatan upaha } \\
\text { Peningkatan aktivitas otot aksesoris } \\
\text { Tanda wajah distress } \\
\text { Sesak napas }\end{array}$ \\
\hline \multirow[t]{9}{*}{ Penilaian objektif } & $\mathrm{PaO}_{2} \leq 50-60 \mathrm{mmHg}$, dengan $\mathrm{FiO}_{2} \geq 0,5$ atau $\mathrm{SaO}_{2}<90 \%$ \\
\hline & $\mathrm{PaCO}_{2}>50 \mathrm{mmHg}$ atau peningkatan $\mathrm{PaCO}_{2}>8 \mathrm{mmHg}$ \\
\hline & $\mathrm{pH}<7,32$ atau penurunan dalam $\mathrm{pH} \geq 0,07$ unit $\mathrm{pH}$ \\
\hline & $\mathrm{RR} / \mathrm{TV}>105$ \\
\hline & $\mathrm{RR}>35 \mathrm{x} /$ menit atau meningkat $\geq 50 \%$ \\
\hline & $\mathrm{HR}>140 \mathrm{x} /$ menit atau meningkat $\geq 20 \%$ \\
\hline & TDS $>180 \mathrm{mmHg}$ atau meningkat $>20 \%$ \\
\hline & TDS $<90 \mathrm{mmHg}$ \\
\hline & Aritmia jantung \\
\hline
\end{tabular}

Keterangan: $\mathrm{PaO}_{2}$ : arterial oxygen tension; $\mathrm{FiO}_{2}$ : inspiratory oxygen fraction; $\mathrm{SaO}_{2}$ : arterial oxygen saturation; $\mathrm{PaCO}_{2}$ : arterial carbon dioxide tension; RR: respiratory rate; TV: tidal volume; HR: heart rate; TDS: tekanan darah sistol

Dikutip dari: Boles, dkk. ${ }^{2}$ 
Tabel 3 Tata Cara Penyapihan

\begin{tabular}{ccccc}
\hline \multirow{2}{*}{ Variabel } & \multicolumn{4}{c}{ Tata Cara Penyapihan } \\
\cline { 2 - 5 } & $\begin{array}{c}\text { Pressure Support } \\
\text { Ventilation }\end{array}$ & CPAP & $\begin{array}{c}\text { Intermittent Trial of } \\
\text { T piece }\end{array}$ & $\begin{array}{c}\text { Once Daily Trial of } \\
\text { T piece }\end{array}$ \\
\hline Jumlah pasien & $3(6 \%)$ & $20(40 \%)$ & $5(10 \%)$ & $22(44 \%)$ \\
Keberhasilan & & & & \\
Berhasil & $3(100 \%)$ & $17(85,0 \%)$ & $4(80,0 \%)$ & $20(90,9 \%)$ \\
Gagal & 0 & $3(15 \%)$ & $1(20 \%)$ & $2(9,09 \%)$ \\
\hline
\end{tabular}

keberhasilan penyapihan, dan juga kegagalan penyapihan.

Analisis data penelitian ini dilakukan secara deskriptif untuk mengetahui gambaran tata cara penyapihan ventilasi mekanik dan angka keberhasilan penyapihan ventilasi mekanik yang dilakukan di ICU RSUP Dr. Hasan Sadikin Bandung. Analisis data univariabel untuk melihat gambaran proporsi variabel masingmasing dengan tipe data kategorik yang akan disajikan secara deskriptif. Untuk data numerik analisis disajikan berupa mean, nilai minimum dan maksimum, standar deviasi, range serta median. Data yang diperoleh kemudian diolah melalui program statistical product and servise solution (SPSS) versi 21.0 for Windows.

Tabel 4 Parameter yang Didapatkan Sebelum Spontaneous Breathing Trial

\begin{tabular}{lcc}
\hline \multicolumn{1}{c}{ Parameter } & $\begin{array}{c}\text { Memenuhi } \\
\text { Kriteria }\end{array}$ & $\begin{array}{c}\text { Tidak } \\
\text { Memenuhi } \\
\text { Kriteria }\end{array}$ \\
\hline pH (n) & 50 & 0 \\
HR (n) & 44 & 6 \\
TDS (n) & 50 & 0 \\
PaCO $_{2}$ (n) & 44 & 6 \\
TDD (n) & 50 & 0 \\
GCS (n) & 44 & 6 \\
RSBI (n) & 50 & 0 \\
Frekuensi napas (n) & 50 & 0 \\
VT (n) & 50 & 0 \\
\hline
\end{tabular}

Keterangan: HR: heart rate; TDS: tekanan darah sistol; TDD: tekanan darah diastol; $\mathrm{paCO}_{2}$ : arterial carbon dioxidetension; GCS: glasgowcomascale; RSBI: rapid shallow breathing index; VT: volume tidal.

\section{Hasil}

Penelitian ini mendapatkan hasil bahwa terdapat empat tata cara penyapihan ventilasi mekanik yang biasa dilakukan di ICU RSUP Dr. Hasan Sadikin Bandung. Penyapihan ventilasi mekanik yang paling banyak dilakukan adalah once daily trial of T-piece sebanyak 22 pasien (44\%; Tabel 3).

Pada penelitian ini didapatkan sebanyak 6 orang pasien (12\%) yang tidak memenuhi kriteria untuk dilakukan SBT pada parameter HR, $\mathrm{PaCO}_{2}$, dan GCS (Tabel 1 dan 2) dan sebanyak 44 orang pasien (88\%) telah memenuhi kriteria sebelum dilakukan SBT (Tabel 4).

Hasil penelitian ini mendapatkan angka keberhasilan penyapihan ventilasi mekanik di ICU RSUP Dr. Hasan Sadikin Bandung mencapai $88 \%$, dan juga didapatkan bahwa pasien yang mengalami kegagalan menunjukkan perbedaan pada parameter $\mathrm{HR}, \mathrm{TDS}, \mathrm{TDD}, \mathrm{PaCO}_{2}, \mathrm{GCS}$, frekuensi napas, dan RSBI dibanding dengan pasien yang berhasil (Tabel 5).

\section{Pembahasan}

Ventilasi mekanik adalah suatu bantuan yang memiliki peranan besar pada pasien-pasien ICU. Sebanyak $20 \%$ pasien yang menggunakan ventilasi mekanik gagal dalam percobaan penyapihan dan lebih dari $40 \%$ lama pemakaian ventilasi mekanik dihabiskan dalam proses penyapihan. Penggunaan ventilasi mekanik yang lama berhubungan dengan peningkatan infeksi, sedangkan ekstubasi prematur diikuti re-intubasi meningkatkan morbiditas serta mortalitas. Penentuan waktu yang tepat untuk penghentian ventilasi mekanik merupakan 
Tabel 5 Parameter yang Didapatkan Sesudah Spontaneous Breathing Trial

\begin{tabular}{|c|c|c|c|}
\hline Parameter & Pasien $(n=50)$ & Berhasil & Gagal \\
\hline Keberhasilan penyapihan (\%) & - & $44(88 \%)$ & $6(12 \%)$ \\
\hline \multicolumn{4}{|l|}{$\mathrm{pH}$} \\
\hline Rata-rata \pm Std. deviasi & $7,405 \pm 0,047$ & $7,406 \pm 0,045$ & $7,39 \pm 0,06$ \\
\hline Median & 7,40 & 7,40 & 7,40 \\
\hline Range & $7,30-7,50$ & $7,30-7,50$ & $7,33-7,47$ \\
\hline \multicolumn{4}{|l|}{ HR (kali/menit) } \\
\hline Rata-rata \pm Std. deviasi & $92,52 \pm 10,44$ & $90,02 \pm 6,18$ & $110,83 \pm 16,85$ \\
\hline Median & 90,00 & 90,00 & 105,00 \\
\hline Range & $77,00-140$ & $77,00-100,00$ & $95,00-141$ \\
\hline \multicolumn{4}{|l|}{ TDS (mmHg) } \\
\hline Rata-rata \pm Std. deviasi & $121,06 \pm 9,57$ & $119,50 \pm 7,49$ & $132,50 \pm 15,41$ \\
\hline Median & 120,00 & 120,00 & 135,00 \\
\hline Range & $108,00-150$ & $108,00-135,00$ & $110,00-150,00$ \\
\hline \multicolumn{3}{|l|}{$\mathrm{PaCO}_{2}(\mathrm{mmHg})$} & $38,15 \pm 5,97$ \\
\hline Median & 35,85 & 35,85 & 35,50 \\
\hline Range & $25,10-50,10$ & $25,10-46,00$ & $34,80-50,10$ \\
\hline \multicolumn{4}{|l|}{ TDD (mmHg) } \\
\hline Median & 70,00 & 70,00 & 86,50 \\
\hline Range & $60,00-92,00$ & $60,00-80,00$ & $75,00-92,00$ \\
\hline \multicolumn{4}{|l|}{ GCS } \\
\hline Rata-rata \pm Std. deviasi & $9,92 \pm 0,44$ & $9,97 \pm 0,15$ & $9,50 \pm 1,22$ \\
\hline Median & 10,00 & 10,00 & 10,00 \\
\hline Range & $7,00-10,00 V_{\mathrm{T}}$ & $9,00-10,00 V_{\mathrm{T}}$ & $7,00-10,00 V_{\mathrm{T}}$ \\
\hline \multicolumn{4}{|l|}{ RSBI } \\
\hline Rata-rata \pm Std. deviasi & $42,33 \pm 10,96$ & $39,91 \pm 8,20$ & $60,06 \pm 13,04$ \\
\hline Median & 40,00 & 40,00 & 60,00 \\
\hline Range & $24,00-80,00$ & $24,00-57,00$ & $44,40-80,00$ \\
\hline $\begin{array}{l}\text { Frekuensi napas (kali/menit) } \\
\text { Rata-rata } \pm \text { Std. deviasi } \\
\text { Median } \\
\text { Range }\end{array}$ & $\begin{array}{c}17,72 \pm 3,59 \\
18,00 \\
12,00-26,00\end{array}$ & $\begin{array}{c}16,90 \pm 2,93 \\
16,00 \\
12,00-24,00\end{array}$ & $\begin{array}{c}23,66 \pm 1,96 \\
24,00 \\
20,00-26,00\end{array}$ \\
\hline $\begin{array}{l}\text { VT }(\mathrm{mL}) \\
\text { Rata-rata } \pm \text { Std. deviasi } \\
\text { Median } \\
\text { Range }\end{array}$ & $\begin{array}{c}430,80 \pm 62,88 \\
410,00 \\
300,00-700,00\end{array}$ & $\begin{array}{c}434,31 \pm 62,22 \\
420,00 \\
300-700\end{array}$ & $\begin{array}{c}405,00 \pm 67,45 \\
400,00 \\
300,00-500,00\end{array}$ \\
\hline
\end{tabular}

Keterangan: HR: heart rate; TDS: tekanan darah sistol; TDD: tekanan darah diastol; paCO $_{2}$ : arterial carbon dioxide tension; GCS: glasgow coma scale; RSBI: rapid shallow breathing index; VT: volume tidal. Data yang diambil sebelum ekstubasi

suatu tantangan. ${ }^{6}$

Penelitian ini dilakukan terhadap 50 orang pasien yang memakai ventilasi mekanik di ICU
RSUP Dr. Hasan Sadikin Bandung didapatkan hasil sebanyak 44 orang (88\%) berhasil dalam proses penyapihan dan sebanyak enam orang 
(12\%) mengalami kegagalan pada penyapihan ventilasi mekanik serta harus dilakukan reintubasi.

Tata cara penyapihan ventilasi mekanik yang dilakukan beberapa ICU rumah sakit berbedabergantung pada kebiasaan dokter ICU masing-masing. Penelitian ini mendapatkan hasil bahwa penyapihan ventilasi mekanik yang paling banyak dilakukan di ICU RSUP Dr. Hasan Sadikin Bandung melalui once daily trial of T piece (44\%) kemudian dilakukan ekstubasi dan memiliki angka keberhasilan yang tinggi sebesar 90,9\%. Pada penelitian sebelumnya juga dinyatakan bahwa tata cara once daily trial of T-piece memiliki angka keberhasilan yang tinggi dalam proses penyapihan ventilasi mekanik. $^{1}$

Tata cara T-piece trial sebelum ekstubasi memiliki beberapa keuntungan, yaitu lebih cocok pada pasien dengan upaya napas spontan yang adekuat, dan tata cara ini yang paling sesuai dengan kondisi normal pernapasan dibandingkan saat mendapatkan tekanan yang diberikan oleh ventilator pada PSV dan CPAP. Sebanyak $80 \%$ pasien yang berhasil dilakukan SBT selama 2 jam dapat dilakukan ekstubasi sehingga penggunaan intermittent trial of $T$ piece tidak lebih baik dari once daily trial of $T$ piece karena memperlama waktu penyapihan. ${ }^{5}$

Penyapihan ventilasi mekanik memiliki beberapa kriteria yang dapat menentukan keberhasilan seorang pasien dapat dilakukan ekstubasi. Pasien harus memenuhi beberapa kriteria untuk menentukan keberhasilan penyapihan. Pada penelitian ini didapatkan $12 \%$ pasien yang gagal penyapihan ventilasi mekanik menunjukkan $\mathrm{HR}$, TDS, TDD, $\mathrm{PaCO}_{2}$, rapid shallow breathing index (RSBI), dan frekuensi napas yang lebih tinggi dibanding dengan pasien yang berhasil penyapihan ventilasi mekanik (Tabel 4).

Parameter TDS menunjukkan perbedaan antara upaya yang berhasil dan gagal. Tekanan darah sistol pasien yang berhasil rata-rata 108-135 mmHg, sedangkan yang gagal ratarata 110-150 mmHg. Walaupun terdapat perbedaan, tetapi nilai TDS rata-rata seluruh pasien masih memenuhi kriteria keberhasilan penyapihan ventilasi mekanik. ${ }^{5}$
Pasien yang gagal penyapihan ventilasi mekanik menunjukkan HR lebih tinggi yang berkisar 95-141 kali per menit. Hal ini sesuai dengan teori yang menyatakan bahwa HR yang disarankan untuk keberhasilan penyapihan adalah kurang dari 140 kali per menit. Pasien yang memiliki HR di atas 140 kali per menit disarankan untuk dilakukan penilaian ulang sebelum penyapihan kembali., ${ }^{2,7}$

Pada kelompok yang berhasil kadar $\mathrm{PaCO}_{2}$ 25,1-46,0 mmHg, sedangkan pada kelompok yang gagal kadar paCO $_{2}$ 34,8-50,1 $\mathrm{mmHg}$. Berdasarkan teori sebelumnya kegagalan yang terjadi pada pasien ini karena kadar $\mathrm{PaCO}_{2}$ sebelum ekstubasi diatas $50 \mathrm{mmHg}{ }^{2}$

Penelitian ini juga mendapatkan hasil penilaian GCS berkisar 7-10V $\mathrm{V}_{\mathrm{T}}$. Pada kelompok yang berhasil didapatkan hasil GCS $9-10 \mathrm{~V}_{\mathrm{T}}$, sedangkan pada kelompok yang gagal GCS $7-10 \mathrm{~V}_{\mathrm{T}}$. Pada teori sebelumnya dinyatakan pasien yang dilakukan penyapihan ventilasi mekanik harus memiliki kesadaran yang adekuat atau GCS $\geq 13$, sedangkan pada pasien yang gagal ini terdapat pasien yang GCS $\leq 13$. $^{5}$

Penilaian RSBI juga penting untuk menilai keberhasilan penyapihan. Pada penelitian ini didapatkan hasil RSBI berkisar 24-80. Kelompok yang berhasil nilai RSBI berkisar 24-57, sedangkan pada kelompok yang gagal berkisar 44,4-80. Hasil penelitian sebelumnya mengatakan bahwa RSBI di bawah 105 dapat menentukan keberhasilan pasien, akan tetapi RSBI sendiri hanya salah satu prediktor keberhasilan penyapihan dan harus memakai parameter yang lain. ${ }^{8-11}$

Pada penelitian ini didapatkan angka kegagalan penyapihan sebanyak enam orang $(12 \%)$ dari semua pasien. Pasien-pasien yang tidak memenuhi kriteria sebelum dilakukan SBT ternyata mengalami kegagalan sesudah dilakukan SBT pada parameter HR yang lebih dari 140 kali per menit, $\mathrm{PaCO}_{2}$ lebih dari 50 mmHg, serta GCS $<13 .{ }^{2,5}$ Peningkatan HR ini terjadi karena peningkatan beban jantung yang dapat disebabkan oleh salah satunya peningkatan beban metabolik selama proses penyapihan atau penyakit sepsis yang belum mengalami perbaikan. Penurunan kesadaran selama proses penyapihan dapat menurunkan 
rangsang napas sehingga akan meningkatkan $\mathrm{PaCO}_{2}$ (hiperkapnia) dan juga hipoksemia. Gangguan neuromuskular juga seperti pada pasien Myasthenia Gravis dapat menurunkan kemampuan otot pernapasan sehingga terjadi hiperkapnia dan hipoksemia. ${ }^{2}$

Kekurangan dalam penelitian ini adalah tidak terdapat data pasien yang meninggal dalam proses penyapihan serta tidak terdapat perbandingan antara tata cara dalam proses penyapihan yang dilakukan sehingga tidak dapat disimpulkan tata cara penyapihan yang paling baik.

\section{Simpulan}

Tata cara penyapihan ventilasi mekanik yang dilakukan di Intensive Care Unit (ICU) RSUP Dr. Hasan Sadikin Bandung yang paling banyak adalah dengan once daily trial of T piece dengan angka keberhasilan keseluruhan penyapihan ventilasi mekanik $88 \%$. Pasien yang berhasil tersebut telah memenuhi kriteria penyapihan sedangkan kondisi sebaliknya pada yang gagal. Penelitian ini juga secara praktis menyarankan setiap dokter ICU harus mengikuti kriteria penyapihan yang ada di ICU RSUP Dr. Hasan Sadikin Bandung.

\section{Daftar Pustaka}

1. Prakash P, Krishna K, Singh P. Weaning modes in mechanical ventilation. Indian Academy Clin Med J. 2007;8(3):222-5.

2. Boles JM, Bion J. Connors A, Herridge M, Marsh B, Melot C, dkk. Weaning from mechanical ventilation. Eur Respir J. 2007; 29:1033-56.

3. Burn SM, Fisher C, Tribble SS, Lewis $\mathrm{R}$, Merrel P, Conaway MR, dkk. The relationship of 26 clinical factors to weaning outcome. Am J Crit Care. 2012;21(1):52-8.
4. Khalil Y, Ibrahim E, Shabaan A, Imam M, Amany EL, Behairy. Assesment of risk factors responsible for difficult weaning from mechanical ventilation in adults. Egyptian J Chest Dis Tubercul. 2012;61:159-66.

5. Marino PL, penyunting. Discontinuing mechanical ventilation. Marino's the ICU Book. Bab 30. Edisi ke-4. Philadephia: Lippincott Williams and Wilkins; 2014.

6. Eskandar N, Michael J, Apostolakos. Weaning from mechanical ventilation. Crit. Care Clin. 2007;23:263-74.

7. Hemant HR, Chacko J, Singh MK. Weaning from mechanical ventilationcurrent evidence. Indian $\mathrm{J}$ Anaesth. 2006;50(6):435-8.

8. Soleimanpour H, Taghizadieh A, Salimi R, Golzari SE, Mahmoodpoor A, Safari $S$, dkk. Rapid shallow breathing index survey, a predictor of non-invasive ventilation necessity in patients with chronic obstructive pulmonary disease exacerbation: an analytical descriptive prospective study. Iran Red Crescent Med J. 2014;16(2):1-6.

9. Crawford J, Otero R, Donnino M, Garcia J, Khazal R, Lenoir T. Rapid shallow breathing index - a key predictor for noninvasive ventilation. Crit Care. 2007;11(Suppl 2): 169.

10. Kheir F, Myers L, Desai NR, Simeone F. The effect of flow trigger on rapid shallow breathing index measured through the ventilator. J Intens Care Med. 2015;30(2):103-6.

11. Bien MY, Lin YS, Shie HG, Yang YL, Shih CH, Wang JH, dkk. Rapid shallow breathing index and its predictive accuracy measured under five different ventilatory strategies in the same patient group. Chinese J Physiol. 2010;53(1):1-10. 